\title{
O ensino de filosofia e a escrita filosófica: a experiência da escrita de si no ensino médio
}

\author{
The teaching of philosophy and philosophical writing: the experience of \\ self-writing in high school
}

\author{
Daniel Salésio Vandresen \\ Professor doutor do Instituto Federal do Paraná, Coronel Vivida, PR, Brasil \\ daniel.vandresen@ifpr.edu.br - https://orcid.org/0000-0001-6662-4703
}

Bárbara Fabiani Lucini

Estudante do Instituto Federal do Paraná, Coronel Vivida, PR, Brasil

barbaraflucini@gmail.com - https://orcid.org/0000-0002-4580-6011

\section{Brenda Fabiani Lucini}

Estudante do Instituto Federal do Paraná, Coronel Vivida, PR, Brasil

brenda_fabiani@outlook.com - https://orcid.org/0000-0001-5342-8789

Recebido em 11 de agosto de 2021

Aprovado em 14 de outubro de 2021

Publicado em 30 de dezembro de 2021

RESUMO: O presente trabalho é uma apresentação dos resultados em pesquisa de iniciação científica no Programa PIBIC-Jr/2020-2021 (IFPR/CNPq), no qual nos propomos a investigar o uso da escrita filosófica como uma técnica de ensino no componente de filosofia nos primeiros anos dos cursos Técnicos Integrado ao Ensino Médio, no Instituto Federal do Paraná, campus Avançado Coronel Vivida. A partir da fundamentação teórica nos conceitos de cuidado de si e escrita de si, descrevemos a formação como uma experiência agonística, ou seja, como uma atitude de inquietação que faz da escrita filosófica uma problematizadora das práticas cotidianas como forma de atenção ao presente e uma relação menos abstrata no ensino. A metodologia dessa pesquisa se compõe de um estudo teórico por meio de revisão bibliográfica e uma investigação prática por meio da análise das escritas filosóficas pelas duas turmas ingressantes no ano de 2020. A análise dos dados das escritas filosóficas, evidencia que a escrita potencializa a problematização de si, contribuindo para a formação de um modo de pensar atento ao que nos acontece no presente.

Palavras-chave: Ensino de filosofia; Escrita filosófica; Cuidado de si; Subjetividade; Projeto PIBIC-Jr.

ABSTRACT The current paper is a presentation on the results of the scientific initiation research in the PIBIC-Jr/2020-2021 (IFPR/CNPq) program, in which we aimed to investigate the use of philosophic writing as a technique of learning in the philosophy subject of first-degree students of the courses Technicians Integrated to High School, in the Instituto Federal do Paraná, campus Avançado Coronel Vivida. Stem from theoretical foundation in the concepts of the care of the self and self- 
writing, we described the education as an agonistic experience, that is, as a restlessness attitude that makes the philosophical writing a tool of problematization of daily practices to pay attention to the present and a less abstract relation to learning. The methodology of this study composes of a theoretical study through bibliographical revision and practical investigation by the analysis of philosophical writings produced by the two entrant classes in 2020. The analysis of philosophical writing data indicates that the writing enhances the problematization of the self, contributing on the development of a way of aware thinking about what happens in the present.

Keywords: Philosophy learning; Self-writing; Care of the self; Subjectivity; PIBIC-Jr Project.

\section{Introdução}

A escrita constitui um instrumento fundamental na formação escolar. No entanto, seu uso nem sempre contribui para potencializar a educação de uma subjetividade autônoma, isto porque, em meio a práticas de ensino, muito comum, do predomínio da transmissão do conhecimento, a escrita ocupa um papel bem definido de reprodução e sem nenhuma relação problematizadora do sujeito que escreve. Diante disso, este texto tem por objetivo apresentar um outro olhar para a escrita, principalmente a escrita filosófica no ensino médio, tensionando a escrita como um exercício problematizador de si mesmo.

O presente texto apresenta os resultados de pesquisa de iniciação científica desenvolvido no projeto intitulado "O ensino de filosofia e a escrita de si como experiência existencial", aprovado no Programa PIBIC-Jr/2020-2021 (IFPR/CNPq)1. Além disso, teve como objetivo analisar a escrita filosófica dos estudantes de ensino médio acerca de quatro temáticas: a adolescência e a importância do cuidado; suas compreensões do mundo; os impactos gerados pelas tecnologias e, por último, a conexão entre filosofia, a razão e o conhecimento científico. Para tanto, utiliza-se como orientação teórica, a noção de cuidado de si resgatado pelo filósofo Michel Foucault em seus estudos sobre o período clássico da filosofia, que indica a necessidade da realização de exercícios para promover um olhar atento sobre si, sobre os outros e sobre o mundo.

Nesse sentido, foram propostas atividades discursivas e reflexivas que pudessem promover uma maior compreensão da relação que os estudantes estabelecem consigo mesmo, para com os outros e com o mundo, de modo que os eles pudessem descrever, por meio da escrita filosófica, seu entendimento do que 
os rodeia. Desse modo, defendemos a escrita de si como uma técnica que possibilita tensionar o filosofar no ensino médio, ao mesmo tempo em que, tendo em vista a importância da prática do cuidado de si, promove a reflexão acerca da própria subjetividade e potencializando o pensamento crítico e atento.

\section{A escrita e o cuidado de si}

O referencial teórico da pesquisa, centra-se na noção de cuidado de si (epiméleiaheautoû) abordado pelo filósofo Michel Foucault, principalmente na obra "Hermenêutica do Sujeito" (2004). E compreende que o cuidado de si constitui "[...] um princípio de agitação, um princípio de movimento, um princípio de permanente inquietude no curso da existência." (FOUCAULT, 2004, p. 11). No entanto, cuidar de si não significa um mero saber cuidar por meio de competências para fazer coisas, mas exercícios de inquietação que nos permitem estar atento ao que se passa conosco e, portanto, constitui o suporte ontológico da relação consigo.

Em sua descrição do cuidado de si, Foucault compreende que epiméleia significa um cuidado que se realiza em uma inquietação como um olhar atento a si mesmo e que também implica em uma atitude de relação com os outros e o mundo. Como afirma:

Primeiramente, o tema de uma atitude geral, um certo modo de encarar as coisas, de estar no mundo, de praticar ações, de ter relações com o outro. A epiméleiaheautoû é uma atitude - para consigo, para com os outros, para com o mundo. [...] O cuidado de si implica uma certa maneira de estar atento ao que se pensa e ao que se passa no pensamento. [...] também designa sempre algumas ações, ações que são exercício de si para consigo, ações pelas quais nos assumimos, nos modificamos, nos purificamos, nos transformamos e nos transfiguramos. (FOUCAULT, 2004, p. 14-15, grifos nossos)

Desse modo, o cuidado de si não é uma atitude egoísta de um saber cuidar enquanto um viver para si, ao contrário, a relação consigo implica uma atenção para com o presente enquanto exterioridade constituinte de subjetividade. Isto é, na atitude para consigo o que se passa no pensamento é um modo particular de encarar as coisas, de um olhar e uma atenção para si produzido a partir da 
inquietação do fora, o que pode ser denominado como dobra de si² $^{2}$ Já uma atitude para com os outros e para com o mundo, indica o modo como a subjetividade se produz a partir de um sentido de estar no mundo, de se afetar pelos (des)encontros e, de praticar ações e atitudes.

Segundo Foucault (2014), entre os estoicos, principalmente Sêneca, Epicteto e Marco Aurélio, a epiméleia se constitui de um conjunto de ocupações para consigo mesmo, um trabalho de si por meio de diferentes práticas, diferentes exercícios de si, como: o exame da consciência, a meditação, os cuidados com o corpo, a leitura, a escuta e a escrita. Deste modo, a partir deste ponto, nosso foco de descrição é sobre a escrita como um exercício do cuidado de si. Foucault mesmo evidencia essa centralidade afirmando: "[...] em torno dos cuidados consigo toda uma atividade de palavra e escrita se desenvolveu, na qual se ligam o trabalho de si para consigo e a comunicação com outrem." (FOUCAULT, 2014, p. 66-67).

Em 1983, Foucault (2012) publica o texto intitulado "A escrita de si", no qual vai aprofundar essa temática definindo a escrita como uma "[...] prática da ascese como trabalho não somente sobre os atos, porém mais precisamente sobre o pensamento [...]." (FOUCAULT, 2012, p. 142). Deste modo, a escrita possibilita um exercício de si por si mesmo pelo trabalho do pensamento, isto é, escrever é colocar em jogo a si mesmo pela inquietação do que se passa no pensamento, "É a sua própria alma que é preciso criar no que se escreve." (FOUCAULT, 2012, p. 149).

Nesta perspectiva, a prática do cuidado de si se caracteriza como uma forma de se atentar aos aspectos que permeiam o próprio ser e os elementos ao seu redor, no sentido de que é preciso converter o olhar do exterior para si mesmo. Deste modo, para a efetivação do pensamento atento, é preciso empregar uma série de exercícios e práticas de si para consigo que permitam que o indivíduo se ocupe dele mesmo, de modo que ele seja capaz de, efetivamente, prestar atenção ao que se passa consigo, com os demais, e com 0 mundo.

Em outro texto de 1983 intitulado "Sobre a genealogia da ética", uma entrevista organizada por Dreyfus e Rabinow, Foucault (1995) aborda o papel da escrita na formação de si. Neste texto o autor descreve sobre o conceito grego de hypomnemata ${ }^{3}$, isto é, sobre o uso da escrita como cuidado de si e dos outros. E ao 
responder uma pergunta sobre como a escrita se articula com a ética de si, afirma: "Nenhuma habilidade técnica ou profissional pode ser adquirida sem exercício; nem se pode aprender a arte de viver, a technètoubiou, sem uma ascese que deve ser tomada como um treinamento de si por si [...]." (FOUCAULT, 1995, p. 272). Nessa passagem, o autor francês evidencia o uso da escrita como uma técnica que possibilita a formação de um modo de vida.

Pierre Hadot (2016) também descreve que o tema da escrita na Antiguidade estava sempre associado ao ensino, e aponta que durante quase três séculos (desde Sócrates até o século I d.C.) ela correspondia a um jogo de perguntas e respostas. Além disso, a escrita não consistia em expor algo de maneira sistemática, mas de um diálogo em que mestre e discípulo estão tratando de questões circunstanciais aos seus problemas, seja de ordem da problematização do saber, seja da ordem do estado moral.

O uso da escrita enquanto repetição sem proporcionar a problematização do sujeito, embora muito presente em nossas práticas de ensino, já estava presente na antiguidade como aponta Foucault (2010) ao analisar a "Sétima Carta" (ou Carta VII) de Platão. Neste texto, o filósofo grego descreve sobre o fracasso de Dionísio na prova da filosofia, recusando a filosofia como exercício de práticas e escolhendo escrever um tratado de filosofia, portanto, um uso da escrita como reprodução sem vínculo com a vida.

A partir disso, defendemos que no ensino de filosofia o essencial não é a transmissão de um conteúdo em que o suficiente é a sua apreensão, fazendo do interlocutor (estudante) um ser passivo, isto é, que cumpre apenas o papel de reproduzir e se reconhecer na verdade do conhecimento transmitido sem colocar em jogo a si mesmo. Ao contrário, a filosofia precisa ser praticada em uma coexistência, em um coabitar problemas, onde não há respostas imediatas e definitivas, mas que se realiza como um "[...] longo caminho da filosofia, isto é, tomar a via rude dos exercícios e práticas [...]." (FOUCAULT, 2010, p. 224). Foucault (2010) desenvolve a ideia de uma filosofia como um modo de coabitar problemas a partir do texto "Sétima Carta" de Platão, no qual o filósofo grego indica que a filosofia não deve ser praticada por fórmulas (mathémata) a serem aplicadas, mas como um 
caminho em que é preciso conviver com os problemas, como afirma o próprio Platão: "Como consequência de um comércio prolongado e de uma existência dedicada à meditação de tais problemas é que a verdade brota na alma como a luz nascida de uma faísca instantânea, para depois crescer sozinha". (PLATÃO, 1975, p. 155). Aprender a coabitar problemas pressupõe que o sujeito esteja em uma relação viva com seu presente por meio de uma atitude inquietante e atenta ao que se passa consigo e em seu modo de agir ético em relação aos outros e ao mundo.

Então perguntamos: o que significa uma escrita filosófica como prática de si? $\mathrm{E}$ como entender a escrita como um modo de coabitar problemas? Como se deslocar de uma prática de ensino de uso da escrita como reprodução do conhecimento e, então, potencializar a escrita como cuidado de si?

A escrita compreendida como uma expressão do exercício de si no pensamento, possibilita a experiência do coabitar problemas. A escrita constitui um modo de coabitar problemas a partir do momento em que deixa de estar atrelada apenas aos seus aspectos técnicos-formais e de seu uso como reprodução do conhecimento, e passa a ser concebida como produção de subjetividades. Isso porquê, segundo Foucault (2006), o discurso constitui uma realidade material, seja como coisa pronunciada ou escrita, que coloca em jogo o sujeito em um sistema de relações de saberes-poderes.

Segundo Geraldi (2015), no capítulo "A aula como acontecimento", a escrita/texto não é resultado de regras preestabelecidas, que podem se tornar um entrave para que no ato de escrever o sujeito possa se expor, como afirma: "Escrever um texto exige sempre que o sujeito nele se exponha, porque ele resulta de uma criação. [...] A escrita se caracteriza pela singularidade de seus gestos." (GERALDI, 2015, p. 98). Ainda, para Geraldi, a escrita deve ser situada nesta perspectiva da aula como acontecimento, na qual defende que o ensino-aprendizagem tem a tarefa de priorizar as perguntas e não as respostas. É fundamental aprender a percorrer caminhos inexistentes, isto porque, "temos aprendido respostas sem sabermos as perguntas que a elas conduziram." (GERALDI, 2015, p. 96).

Nessa perspectiva, também é preciso coabitar o tempo da escrita. Não de um tempo cronológico que domina as práticas de ensino que visam apenas produzir 
respostas, mas de uma compreensão do tempo como kairós ${ }^{4}$ em que se mantém uma relação viva com o presente por uma atitude atenta para coabitar o pensamento em seu acontecimento. Ou seja, não podemos elidir a ocasião do pensamento problematizador para se adequar ao cumprimento das metas avaliativas.

Enfim, a escrita tem um importante papel na formação da subjetividade. A escrita manifesta a marca de uma experiência subjetiva no uso da linguagem como interpretação do mundo no presente que nos constitui. A escrita, assim como o discurso/fala, pode ser tanto de dominação quando de liberação, ou seja, torna-se dominação quando aprisiona o indivíduo em determinados modos de ser e de fazer, como é o caso da escrita reprodutora; já como liberação, possibilita rupturas e aberturas para a criação de novas formas de viver. Portanto, torna-se fundamental praticar um uso da escrita como exercício de si e como formação de uma subjetividade autônoma. A partir do exposto, defendemos que a escrita filosófica como um modo de coabitar problemas constitui um importante elemento na formação de si no ensino de filosofia no ensino médio.

\section{Metodologia}

O presente projeto de pesquisa de iniciação científica desenvolvido no Programa PIBIC-Jr/2020 (IFPR/CNPq), foi realizado como atividade de investigação teórica e prática sobre o uso da escrita filosófica pelas duas turmas ingressantes no ano de 2020 no Ensino Médio Integrado do IFPR campus Avançado Coronel Vivida. Sendo assim, a metodologia desta pesquisa se compõe de um aprofundamento teórico por meio de revisão bibliográfica dos conceitos fundamentais do projeto e de uma investigação prática por meio da análise qualitativa das atividades de escrita filosófica.

No ano de 2020 foram realizadas quatro atividades de escrita filosófica, sendo uma produção por bimestre via ferramenta de fórum na plataforma Moodle, instrumento que além de permitir a apresentação da reflexão escrita também potencializa o diálogo entre os envolvidos. A atividade foi realizada com os estudantes ingressantes no ano de 2020 no Ensino Médio Integrado dos cursos 
técnicos em Administração e Cooperativismo no IFPR, Campus Avançado Coronel Vivida, totalizando um público de 83 estudantes (número de alunos matriculados nas duas turmas no término do ano).

A atividade proposta em cada bimestre consistia em realizar uma reflexão a partir do conteúdo desenvolvido no momento. Por isso, cada uma das quatro atividades foi apresentada com uma introdução textual e, por meio de perguntas que instigavam a reflexão e o diálogo entre os estudantes. As questões propostas buscavam provocar o pensar sobre si mesmos, sobre a existência e a relação consigo, com os outros e com o mundo. Assim, os estudantes deveriam realizar uma reflexão que o conduzisse à problematização do conteúdo e apresentá-lo em um texto dissertativo. A partir desses critérios, a escrita de cada estudante também foi avaliada para atribuição de um conceito no componente de filosofia, como uma das atividades avaliativas no bimestre.

O diagnóstico da escrita foi realizado por meio de relatórios e discussão entre os pesquisadores (orientador, a bolsista e uma aluna voluntária), o qual teve como parâmetro uma análise qualitativa fundamentada na descrição arquegenealógica dos discursos ${ }^{5}$. Nessa forma de análise, nosso objetivo é compreender o modo como a vida dos sujeitos é formada pelas práticas cotidianas de exercícios de si, no qual a escrita constitui um desses elementos de produção de subjetividades.

\section{Análise das escritas filosóficas em 2020}

A análise das escritas teve como norte a descrição de Foucault (2004) sobre a noção de cuidado de si como uma relação consigo, com os outros e com o mundo. Com esse diagnóstico, buscamos apontar as principais ideias que aparecem nas escritas dos estudantes, tendo sempre como foco perceber qual é a transformação que está ocorrendo na relação consigo, ou seja, identificar como cada estudante expressa uma mudança de olhar, de pensar, de se comportar. Na atitude para consigo, buscamos descrever o modo como os estudantes expressam um modo particular de encarar as coisas, um olhar e uma atenção para si. $\mathrm{Na}$ atitude para com os outros, visamos caracterizar algo que expresse uma transformação de si 
produzida a partir de uma relação com outra(s) pessoas, e na atitude para com o mundo procuramos apresentar algo que expresse uma transformação de si produzida a partir de um sentido de estar no mundo e de praticar ações.

No ano de 2020 foram realizadas quatro produções textuais, as quais seguem descritas abaixo:

\section{A adolescência e o cuidado}

a) Apresentação da atividade

Tal atividade propôs que os estudantes realizassem uma reflexão sobre o período da adolescência, sobretudo acerca de quais são suas percepções ao vivenciar essa etapa de suas vidas em meio aos desdobramentos da pandemia do coronavírus - voltando-se, principalmente, para como foram afetados pelo isolamento social. Nesse sentido, o objetivo primordial foi analisar quais eram os questionamentos despertados nos estudantes nesse período, bem como sobre quais eram seus entendimentos em torno do cuidado, necessário nesta mesma conjuntura permeada pelo COVID-19.

\section{b) Análise da atividade}

A partir da investigação das reflexões dos alunos, pode-se perceber aspectos relacionados a atitudes que estabelecem consigo mesmos, com os demais e com o mundo. Inicialmente, demarcando a relação que estabelecem de si para si próprios, destaca-se que os estudantes descrevem estarem passando por um processo de autoconhecimento, de reconhecimento dos próprios gostos, vontades, princípios e capacidades, além de refletirem sobre a passagem do tempo e sobre o próprio passado. Além disso, os estudantes se mostram estar em um momento introspectivo, no qual buscam se perceber no mundo, o seu modo de vida e como são afetados pelas convenções sociais de seu tempo. Em segundo plano, a relação que estabelecem como os outros é permeada por um ideal de responsabilidade, no sentido de que é preciso cuidar não apenas de si mesmo, mas também dos demais. É a relação com os demais que possibilita o seu autorreconhecimento no mundo 
como indivíduos únicos e a necessidade de percebermos o outro, pois somente assim entendemos o cuidado como algo a ser transferido. Por fim, destaca-se a percepção do mundo na fase da adolescência, que passa, em grande parte, pelo sentimento da incerteza frente a um futuro indefinido. Este tópico também é permeado por visões pessimistas e pela insegurança em relação a um futuro próximo, no que diz respeito, principalmente, aos âmbitos sociais, econômicos, políticos e ambientais. Contudo, muitos demonstram ter esperança por uma ordem social mais justa e solidária.

\section{Como vejo o mundo}

a) Apresentação da atividade

Neste tópico, foi feita uma reflexão a partir da percepção dos estudantes sobre o mundo. Nesse sentido, foi proposto aos alunos que refletissem e compartilhassem seu discernimento individual sobre como entendem o mundo no qual vivemos, baseando-se em duas prerrogativas iniciais: quais questionamentos os estudantes achavam pertinentes para compreender a atual situação do mundo e como entendiam a si mesmos como sujeitos do mundo, e quais são os sentimentos que essa relação desperta neles.

\section{b) Análise da atividade}

A partir da análise geral da atividade e da reflexão dos alunos, foram destacados comportamentos relacionados à percepção e ao cuidado de si mesmo, dos outros e do mundo em geral. Em primeiro plano, sobre a relação que estabelecem consigo mesmos, muitos estudantes relatam a preocupação em relação ao seu futuro, imaginando possíveis cenários que as suas vidas podem traçar. Paralelamente, também ressaltam o desejo de aproveitar ao máximo o presente e os acontecimentos cotidianos, como suas famílias e amigos. Ademais, os estudantes refletem sobre as suas crenças pessoais, levando em consideração a existência de algo "superior", e, por consequência, suscitando questões existenciais sobre qual o nosso papel no mundo e qual o sentido da vida. Em relação ao período da pandemia do COVID-19, os estudantes evidenciam o período de isolamento 
social como uma oportunidade para se atentar ao seu eu e aprender sobre si próprio. No que diz respeito à relação do cuidado em relação aos outros, muitas das reflexões perpassam o repúdio por ações preconceituosas e discursos de ódio para com determinados grupos sociais, ao passo em que os estudantes parecem lamentar tal tipo de atitude e se mostram esperançosos pelo respeito à diversidade e possibilidade de discussão de determinados temas. Acerca da preocupação em relação ao mundo, a maioria dos estudantes relata uma angústia em relação ao futuro da humanidade, sobretudo no que diz respeito ao meio ambiente e as possíveis consequências para a saúde e vida humana.

\section{Reflexão sobre as tecnologias}

a) Apresentação da atividade

A partir da problemática acerca do impacto das tecnologias no processo de construção do indivíduo e da relação estabelecida entre o homem e os aparatos tecnológicos, foi proposto aos alunos que apresentassem o que pensavam sobre o tema. Por meio dessa atividade, buscou-se analisar como os alunos percebem a si, ao mundo e as relações que estabelecem com outros em um cenário permeado pela presença da tecnologia de um modo geral.

b) Análise da atividade

Em primeiro plano, as reflexões realizadas pelos alunos se centram em um processo de "voltar a si mesmo", ou seja, ao olhar atento acerca dos impactos que a tecnologia acarreta neles mesmos, enquanto indivíduos. Diante disso, os alunos refletem sobre como a tecnologia impacta diferentes aspectos de suas vidas, tanto na esfera social quanto na emocional. Eles constatam que, diante de uma alteração em suas rotinas (durante o período de pandemia), e a consequente intensificação da relação com diferentes aparatos tecnológicos, seus comportamentos e suas emoções são afetadas. Além disso, pontuam que sua aproximação com estes, deixaram-nos, por vezes, confusos e desorientados. Sendo assim, apontam ser 
necessário esforços a fim de se adaptarem ao cenário de mudança, buscando por uma transformação de si.

Paralelamente, os alunos também expõem suas percepções sobre como a tecnologia afeta suas relações interpessoais e interações sociais. Suas reflexões apontam para como a tecnologia pode auxiliar no processo de comunicação, visto que permite a conexão de pessoas à longa distância por diferentes meios e de distintas formas, mas como, ao mesmo tempo, a comunicação virtual pode não ser tão efetiva quanto as interações presenciais. Diante de uma situação de distanciamento social, na qual a proximidade física deve ser evitada, os alunos refletem sobre o quão importante e insubstituíveis são as interações sociais presenciais, e exprimem sentir falta do convívio presencial e da familiaridade do ambiente escolar.

Ademais, os alunos se mostram atentos ao que se passa no mundo e ao seu entorno ao passo que expressam suas frequentes preocupações acerca dos impactos que a tecnologia pode gerar, principalmente, em nosso modo de vida, concepções e hábitos. Eles refletem sobre como a tecnologia adentrou nossa vida, e sobre como ela alterou nossos comportamentos e nossa cultura ao decorrer do tempo, chegando ao ponto de nos tornarmos dependentes dela. Dentre as mudanças causadas pela imersão tecnológica a qual somos expostos, eles ressaltam sobre como nossos pensamentos e escolhas são afetados. Por exemplo, a influência da disseminação de notícias falsas e a mudança no nosso padrão de consumo. Ademais, refletem sobre como a tecnologia é capaz de alterar nossas formas de comunicação e percepções do mundo, modificando a forma como nos expressamos e sentimos.

\section{Reflexão sobre a razão e a ciência}

a) Apresentação da atividade

Buscou-se analisar a percepção dos alunos sobre a relação entre a filosofia, a razão e o conhecimento científico no ambiente em que estão inseridos. A análise se desenvolveu através de duas principais perguntas, sendo o primeiro questionamento 
sobre o motivo pelo qual é importante refletir sobre a ciência e o segundo acerca de como os estudantes acreditam que o homem percebe o conhecimento científico, sobretudo em um contexto no qual há atitudes de negação perante a ciência.

b) Análise da atividade

De modo geral, os estudantes apontam como dúvidas e questionamentos pessoais, orientam a busca por uma explicação lógica e confiável para a compreensão do mundo. Sendo assim, muitos enfatizam a colocação de uma pergunta como antecedente à formulação da ciência. Desse modo, eles reiteram como a razão, característica do conhecimento científico, é determinante na construção de nossas crenças pessoais e daquilo que entendemos como "verdade". É também neste sentido que apontam o negacionismo científico como fruto do conflito entre as crenças pessoais impulsionadas por motivações ideológicas e políticas, sem respaldo científico, e entre afirmações enunciadas pelo conhecimento científico. Diante disso, colocam a importância da postura autônoma e questionadora no que diz respeito à busca pela verdade orientada pela razão, buscando sempre se manter informado por via de fontes confiáveis e com comprometimento com a ciência

Os alunos evidenciam como a ciência se relaciona diretamente com o cuidado para com os outros, ao passo em que os estudos científicos e o aprimoramento da técnica possibilitam a orientação sobre como assegurar o bem-estar social. Assim, a "evolução" da ciência possibilitou a determinação dos melhores métodos de tratamento médico e o descobrimento da cura de algumas doenças, influenciando no aumento da qualidade de vida das pessoas. Este aspecto é observado tanto no âmbito do bem-estar físico, quanto no que diz respeito à saúde mental, visto que o crescimento dos estudos da psicologia e da psiquiatria visam pelo bem-estar emocional e mental. Como exemplo, muitos citam a pandemia do COVID-19, quando a ciência teve um papel essencial na busca por esclarecimentos sobre o vírus em circulação, divulgando maiores informações sobre esse, com o objetivo de zelar pela vida e evitar maior número de infecções e de mortes. Diante disso, é 
também evidenciado como a troca e o acúmulo de conhecimento transmitido de geração a geração é um fator determinante para a produção científica, ao passo que as previsões da ciência se tornam mais apuradas e confiáveis no decorrer do tempo. Sendo assim, as relações para com o outro, com o objetivo de transmissão do conhecimento, são de suma importância para o desenvolvimento da ciência.

Além disso, pode-se dizer que o negacionismo científico também produz efeitos a partir da relação que estabelecemos com outros, uma vez que indivíduos com postura de negação diante da ciência possivelmente foram influenciados a pensar dessa maneira após visualizarem essa postura sendo defendida por outras pessoas. Sendo assim, conforme exposto pelos alunos, percebe-se que concepções tidas como individuais são influenciadas pelas ideias difundidas pelas pessoas ao nosso redor, levando a uma posição de subordinação a esses preceitos, visto que, com muita frequência, são defendidas como sendo verdades universais. É nesse sentido que destacam a importância da atitude de valorização do conhecimento científico, visto que esse tem um papel essencial na manutenção da vida e na asseguração do bem-estar físico e emocional.

Ademais, os estudantes sinalizam como a ciência é de extrema importância para a compreensão do mundo em que vivemos, pois nos auxilia a entender e compreender os processos que ocorrem em nossa sociedade, sejam esses no âmbito político, econômico, social ou no entendimento dos processos biológicos e os fenômenos da natureza. Assim sendo, destacam o caráter cotidiano que o conhecimento científico toma em nossas vidas, pois ele permite o entendimento de acontecimentos diários e palpáveis em nossa vivência, mesmo que por vezes o rigor científico presente no âmbito acadêmico pareça distante em determinados espaços e ambientes onde estamos inseridos. É muito presente, também, no relato dos estudantes, a ideia de que a evolução da ciência promoveu, ao longo do tempo, o aprimoramento de certos aspectos de nossa sociedade, ao passo em que auxiliou na transformação de nossos modos de vida e de pensar, hábitos e costumes. Alguns exemplos são a determinação de leis científicas, correntes de pensamento e aprimoramento do conhecimento médico. 


\section{Considerações finais}

A análise das escritas filosóficas apontou, em síntese, para o fato de que, primeiramente, acerca da adolescência e da necessidade do cuidado, os estudantes reconhecem que o cuidado é uma prerrogativa essencial para a compreensão da própria identidade e para o reconhecimento de suas relações com os outros e com o mundo. Acerca da atividade sobre a compreensão do mundo, percebe-se que os estudantes buscam o entendimento do mundo em que vivem e se preocupam com seus próprios futuros, com o do mundo e com o futuro dos demais e, evidenciam, dessa forma, a importância do pensamento atento para compreensão do ambiente.

No que diz respeito às tecnologias, os estudantes se mostram atentos aos impactos gerados pela tecnologia nos âmbitos individual, principalmente como a tecnologia afeta suas emoções; coletivo, nos impactos gerados em seus vínculos interpessoais; e geral, nos efeitos que a tecnologia gera e ainda irá gerar no mundo. Por último, na relação entre razão e ciência, os alunos apontam tais preceitos como influentes na construção de nossas crenças pessoais, como essenciais para tomar decisões e disseminar conhecimentos e, ainda, imprescindíveis na asseguração de nossa qualidade de vida e compreensão do mundo.

Diante do exposto, ressaltamos que a utilização da escrita filosófica no ensino de filosofia se mostra uma técnica eficaz para potencializar a aprendizagem e engajar a participação dos estudantes em discussões de cunho filosófico. Dessa maneira, por meio da escrita filosófica, os estudantes puderam refletir sobre as próprias concepções e sobre os aspectos que os permeiam. Assim, a escrita filosófica constitui um importante elemento na formação de si e se faz necessário usá-la como técnica de coabitar o pensamento e a vida.

Enfim, percebemos que o emprego da escrita filosófica, além de benéfico para o processo de reflexão sobre o conhecimento, também é capaz de promover a efetivação de um pensamento atento sobre si mesmo, sobre os demais e sobre o mundo. Assim, por meio da descrição de seus pensamentos e modos de ver o mundo, os estudantes são capazes de exteriorizar as próprias concepções e estabelecer um vínculo de cuidado de si para si, de si para com os outros e para 
com o mundo. Portanto, a escrita filosófica como um modo de escrita de si, constitui uma técnica que possibilita tensionar o filosofar no ensino médio.

\section{Referências}

DELEUZE, Gilles. Foucault. Tradução de Claudia Martins. São Paulo: Brasiliense, 2005.

FOUCAULT, Michel. A Ordem do Discurso: aula inaugural no Collège de France, pronunciada em 2 de dezembro de 1970.13 ed. Tradução de Laura F. A. Sampaio. São Paulo: Loyola, 2006.

FOUCAULT, Michel. A verdade e as formas jurídicas. 3 ed. Tradução de Roberto C. M. Machado e Eduardo J. Morais. Rio de Janeiro: NAU Editora, 2005.

FOUCAULT, Michel. A Hermenêutica do Sujeito. Tradução de Márcio A. da Fonseca e Salma T. Muchail. São Paulo: Martins Fontes, 2004.

FOUCAULT, Michel. Ética, Sexualidade, Política. 3. ed. Tradução de Elisa Monteiro e Inês A. D. Barbosa. Rio de Janeiro: Forense Universitária, 2012.

FOUCAULT, Michel. História da Sexualidade 3: Cuidado de Si. São Paulo: Paz e Terra, 2014.

FOUCAULT, Michel. Sobre a genealogia da ética: uma revisão do trabalho. In: RABINOW, Paul; DREYFUS, Hubert. Michel Foucault, uma trajetória filosófica: para além do estruturalismo e da hermenêutica. Tradução de Vera P. Carreto. Rio de janeiro: Forense Universitária, 1995, p. 253-278.

FOUCAULT, Michel. O governo de si e dos outros: curso no Collège de France. Tradução de E. Brandão. São Paulo: Editora WMF Martins Fontes, 2010.

GERALDI, João Wanderley. A aula como acontecimento. In: A aula como acontecimento. São Carlos: Pedro \& João Editores, 2015, p. 81-101.

HADOT, Pierre. A filosofia como maneira de viver: entrevista de Jeannie Carlier e Arnold I. Davidson. Tradução de Lara C. de Malimpensa. São Paulo: É Realizações, 2016.

PLATÃO. Diálogos: Fedro - Cartas - O primeiro Alcibíades. Belém: Ed. UFPA, 1975. 
VANDRESEN, Daniel Salésio; HOLTZ, Isabela Strapazzon; COLLA, Rafael Antonio. O ensino de filosofia e a escrita de si: o uso da redação de cartas filosóficas no Ensino Médio técnico. Eleuthería - Revista do Curso de Filosofia da UFMS, 5 (Especial), p. 91-105, 2020.

\section{Notas}

${ }^{1}$ Este projeto é uma continuidade da pesquisa desenvolvida no PIBIC-Jr/2019-2020 (IFPR/CNPq), cujos resultados estão publicados em Vandresen, Holtz, e Colla (2020).

${ }^{2}$ Segundo Deleuze (2005) o que os gregos fizeram "Foi vergar o lado de fora, em exercícios práticos. [...] uma relação de força consigo, um poder de se afetar a si mesmo, um afeto de si por si. [...] Eis o que fizeram os gregos: dobraram a força, sem que ela deixasse de ser força." (DELEUZE, 2005, p. 107-108). Nesse sentido, o pensamento como dobra deve ser entendido como uma atividade de subjetivação, isto significa, que não é apenas uma relação com o dentro, mas que enquanto dobra do lado de fora, a constituição de si se dá em uma relação de força com os poderes. Dobrar o pensamento significa afetar-se pelas relações de força que produzem o deslocamento de si.

${ }^{3}$ Segundo Foucault (1995) hypomnemata, na cultura antiga, designa escritos que serviam para memória material de coisas lidas, ouvidas ou pensadas e eram constituídos de apontamentos, registros públicos, cadernos de anotações pessoais e como uso em guia de conduta (livro de vida).

${ }^{4}$ Foucault define Kairós como: "A ocasião é o bom momento, e o bom momento é definido pelo fato de que, num momento dado, poderia haver como que uma bonança, um clareado céu, um momento favorável para tomar o poder." (FOUCAULT, 2010, p. 198).

${ }^{5}$ Em Foucault a análise arquegenealógica dos discursos pode ser caracterizada como: "O discurso é esse conjunto regular de fatos linguísticos em determinado nível, e polêmicos e estratégicos em outro. Essa análise do discurso como jogo estratégico e polêmico é, a meu ver, um segundo eixo de pesquisa". (FOUCAULT, 2005, p. 9). Nesta passagem, Foucault está caracterizando o segundo eixo de suas pesquisas que é o metodológico, o qual considera o discurso para além da análise linguística, porque considera o discurso como um jogo estratégico, uma luta entre os saberespoderes de dominação e seus modos de escapar das sujeições.

\section{(c)(1)(8)}

This work is licensed under a Creative Commons Attribution-NonCommercial 4.0 International (CC BY-NC 4.0) 